\title{
Touch Screens for the Older User
}

\author{
Niamh Caprani, Noel E. O'Connor and Cathal Gurrin \\ CLARITY: Centre for Sensor Web Technologies \\ Ireland
}

\section{Introduction}

"I suspect we will be seeing touch screens used for more applications than ever before" (Shneiderman, 1991).

It has been 20 years since Ben Schneiderman predicted that there would be an increase in the use of touch screen applications yet it has been only in recent years that this prediction has come to pass. The concept of a touch screen computer was first introduced in 1965 by E.A. Johnson who described the possibilities of touch screen technology to support air traffic controllers. In this article Johnson describes how "the touch display coupled to a computer can be considered as a keyboard", a novel approach at the time. Touch screens were brought into the public domain in 1971 by Elographics, Inc. which instigated the development of public touch screen technology such as automated teller machines (ATMs) and information kiosks (Brown et al., 2011). Another milestone in the history of touch technology was the introduction of the personal touch screen computer, HP-150, developed by Hewlett-Packard in 1983 (Sukumar, 1984). The purpose of this early design was to offer individuals an intuitive technology option. Although touch screen systems have maintained this intuitiveness and ease of use over the years, problems that existed with early systems still provide challenges for designers and developers to this day.

It is largely due to the release of the Apple iPhone and iPad that was quickly followed by similar offerings from competitors that we have recently seen a touch screen revolution. Today, touch screen devices are easily available, portable and relatively inexpensive. Furthermore, commercial touch screen technology offers a balance between accessible interaction and aesthetics. This is welcome news for the older user. Although older adults for the most part have positive opinions about technology (Mitzner et al., 2010), they are less likely to use technology compared to younger individuals (Fisk et al., 2009). However, the main predicting variables of technology acceptance for older adults are usefulness and ease of use (Bouwhuis, 2003; Selwyn, 2004; Mitzner et al., 2010). These are variables which would benefit all users of technology.

There are essentially three ways in which a person can use a touch screen device. These are: (1) one user interacting with a device (e.g. a mobile phone); (2) multiple users interacting with one device at the same time; and (3) multiple users interacting with one device at different times (e.g. tablet computer). Although it is worth noting the possibility for multiuser interaction with a touch screen tabletop, such as the DiamondTouch or Microsoft Surface, throughout this chapter we will mostly be referring to one individual interacting with a touch screen system. 
In this chapter we will discuss the implications of touch screen technology for the older user. Firstly in section 2 we will look at the definition of an "older adult" and outline the general characteristics and capabilities of this age group. In section 3 we will discuss the advantages and disadvantages of touch screens and refer to research aiming to increase the usability of touch screens for older adults. Finally, in section 4 we will provide examples of touch screen applications that have been developed and researched in the public, healthcare, home and social domain.

\section{Characteristics of the older user}

Older people are living longer and the older population is gradually increasing. This demographic shift has motivated researchers from various disciplines to work out ways to improve the quality of life for older people, alleviating the effects of ageing through medication and assistive technology (Astell et al., 2010). In a study focused on population projections over 27 European countries, Mamolo and Scherbov (2009) showed that there will be an overall population shrinkage with an expansion of the elderly population. One person out of four is projected to be over the age of 65 by the year 2030. Figure 1 taken from Mamolo and Scherbov's report illustrates the growing population of older individuals between the years 2007, 2020 and 2030. These statistics emphasise the need for researchers to come up with innovative approaches to support older adults and to embrace this group as potential technology users.

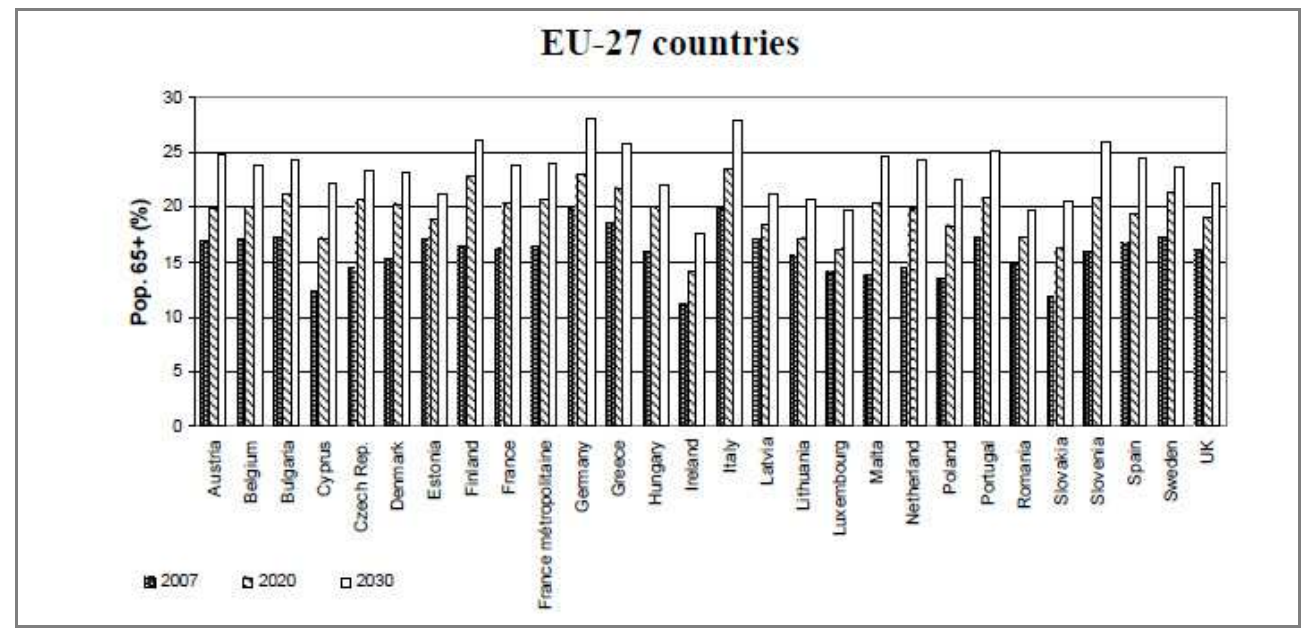

Fig. 1. Population projections for individuals 65+ years for the years 2007, 2020 and 2030, across 27 European countries; Mamolo \& Scherbov (2009).

\subsection{Defining the "older adult"}

Age classification is not a straightforward process as many variables impact the rate at which a person ages. Chronological age markers are the most common measurement used, for example, determining the age of retirement. However this does not take into account biological, psychological and social factors. Newell (2008) groups older people into three 
broad categories: (1) Fit older people, who do not appear, or consider themselves, disabled but whose functionality, needs and wants are different to those they had when they were younger, (2) Frail older people, who would be considered to have a "disability" and in addition have a general reduction in many other functionalities, and (3) Disabled people who grow older, whose long-term disabilities may have affected the ageing process, and whose ability to function can be critically dependent on the other faculties, which will also be declining. Fisk et al. (2009) state that although individual differences exist, generally older adults have common biological, psychological and social characteristics. They suggest grouping older adults into two groupings: (1) The younger-old, ranging in age from 60-75; and (2) The older-old, for individuals over the age of 75 years. We will briefly outline the characteristics of ageing in the next section.

\subsection{Age-related issues and implications for design}

Understanding or, at the very least, being aware of the capabilities and limitations of older users can help to guide designers and developers to create more useable technologies. As we grow older we change and develop, increasing some skills, losing others and learning to compensate for those in decline (for review see Bosman \& Charness, 1996). Some of these changes have more implications on how we interact with technology (e.g., vision problems) compared to others (e.g., greying hair). The characteristics that we as designers are concerned about include perceptual, psychomotor, cognitive and physical changes (see figure 2 for summary). Perceptual abilities, most commonly for vision and hearing, generally begin to show signs of decline from a relatively young age. Approximately half of all men over the age of 65 and $30 \%$ of women suffer hearing loss, and most people notice visual problems around the age of 40 (Fisk et al., 2009). These figures highlight the importance for interfaces to provide clear adjustable output from devices (Charness \& Jastrzembski, 2010). Designers of technology systems should accommodate for this by displaying appropriately sized text and design features, using high contrast colours and including adjustable audio output at low frequencies (Fisk et al., 2009; Hawthorn, 2000). Multimodal output would also increase the usability of a design for an older user.

Cognitive changes also have a significant influence for older users. Age-related differences in cognitive functioning can be seen to stem from the reduction of cognitive resources available, impairing older adults' ability to carry out cognitively demanding processes (Kester et al., 2002). For example, working memory, the ability to store and retrieve new information, along with declining information processing speed, effects how older adults learn and interact with new devices. Many systems rely on a person's ability to keep information active however this is unrealistic for older users unless they are proficient users. Therefore designers should make use of appropriate feedback to the user informing them where they are in the system and where they have been. Simple use of text, colour and icons can significantly reduce confusion and increase ease of use. An age-related deterioration of attention skills also means that extraneous or distracting information on screens can cause further complications for the older user.

Older adults show changes in their physical abilities, due to loss of muscle mass and flexibility. Physical problems can also occur as a result of accidents and falls (common with frailer older adults) and age-related conditions such as arthritis and stroke. In computer use this can result in difficulties grasping a mouse, and positioning and controlling the curser 
(Hawthorn, 2000). Even with "normal" ageing there is an overall slowness of movement and older users may find it difficult to make precise selections of small interface targets. Frail older users may also have problems pressing buttons on devices such as television remote controls. Matching the input device to the task can go some way to supporting these issues (Charness \& Jastrzembski, 2010; Rogers et al., 2005). To reduce these problems, designers should implement large targets for accurate cursor positioning, reduce scrolling when possible and allow for slower response times. Touch screen interfaces are more frequently being used to assist the technology experience of older adults as they require direct input, require large button targets and eliminate the need for multi-components (e.g., a desktop uses a mouse, keyboard and monitor) (Jin et al., 2007).

Touch screen technology can accommodate for some of these age-related limitations. The technology itself requires that the screen size, even on mobile devices, is larger than nontouch devices. In addition, designers of touch screen interfaces incorporate virtual buttons that are large enough for a finger to press accurately. These features mean that items are larger on the screen, making them (a) easier to see and (b) easier to select accurately. Furthermore, the use of virtual buttons on the screen means that older users do not require as much strength to select a target, and they also do not have to divide their attention between the keypad and the screen.

\begin{tabular}{|c|c|c|c|}
\hline \multicolumn{5}{|c|}{ CHARACTERISTICS OF AGENG } \\
\hline Perceptual & Psychomotor & Cognitive & Physical \\
\hline $\begin{array}{c}\text { Vision and } \\
\text { hearing decline. }\end{array}$ & $\begin{array}{c}\text { Slowness and } \\
\text { imprecision in } \\
\text { motor control. }\end{array}$ & $\begin{array}{c}\text { Decline in } \\
\text { working memory, } \\
\text { divided attention } \\
\text { and information } \\
\text { processing speed. }\end{array}$ & $\begin{array}{c}\text { muscle strength } \\
\text { and dexterity. }\end{array}$ \\
\hline
\end{tabular}

Fig. 2. Summary of age-related changes that have implications on interactions with technology.

\subsection{Older adult's use of technology}

\subsubsection{Technology experience}

The number of studies investigating computer use by older adults has progressively increased over the last twenty years (Wagner et al., 2010). This interest stems from a diverse range of research disciplines including, human computer interaction, education and gerontology to name but a few. Although older adults are currently the fastest growing 
group of Internet users (Wagner et al., 2010), they are less likely to use technology compared to younger groups (Czaja et al., 2006; Czaja \& Lee, 2007; Goodman et al., 2003; Morris et al., 2007). Older people generally have a positive attitude towards technology and will use a product if they have a need for it (Fisk et al., 2009). Positive attitudes are also more likely to be expressed towards everyday devices in the home, such as the television, microwave and house alarm (Coleman et al., 2010). Although modern versions of these devices are digital, older users are familiar and comfortable with them. Czaja et al. proposed that the factors predicting older adults' use of computers are age, education, fluid intelligence (abstract problem solving ability), crystallised intelligence (cultural knowledge), computer efficacy (belief about ability), computer anxiety and prior technology experience.

Morris et al. (2007) investigated the older adults' use of computers and the Internet. In total, 473 older adults participated in this survey. The responses showed that word processing and keeping in contact with others (e.g. email) were the most frequently used computer and Internet features. This finding was supported by previous research carried out by Selwyn (2004). Of the Internet users in Morris's survey, 64\% stated that it had a positive impact on their lives. The most common reason for not wanting to learn to use a computer or the Internet was that they were simply "not interested". Other reasons given were feeling too old to learn, believing it to be too difficult, and not having access to a computer. Selwyn (2004) found that as circumstances change, so do people's interest or lack of interest in technology. For example, an older person may become interested in using email after their grandchild emigrates abroad, and another older person who used a computer as part of their profession may choose a computer free life after retirement.

\subsubsection{Acceptance barriers}

So why are older adults less likely to use computers compared to their younger counterparts? As mentioned in the paragraph above, those older individuals who are using computers believe that the technology enhances their lives (Morris et al., 2007) and previous use of technology has an influence on the acceptance of new technologies (Czaja et al., 2006). Similarly, Jay and Willis (1992) tested the attitudes of 101 older adults before and after a two week computer training program. It was found that direct computer experience can significantly modify attitudes, particularly in relation to computer efficacy and comfort. However in Morris et al.'s study, when non-Internet users were asked if there were any factors that would encourage them to learn in the future, the majority (60\%) said there was nothing that would influence them. As well as attitude and age-related changes to perceptual, cognitive, and physical abilities acting as barriers for older adults learning new technologies, there are the issues older people have in relation to their privacy, particularly regarding monitoring technologies (Charness \& Boot, 2009).

In some situations, older adults are forced to interact with technology to avail of services. For example, many transport services require travellers to purchase their ticket from a machine. Some airlines even have a fee to check-in at person serviced desks to encourage customers to check-in online. Instead of using these technologies it is more than likely that older non-computer users would either avoid the situation or ask a friend or family member to do it for them (Coleman et al., 2010). If users are not given a choice of transaction method, then it is crucial for the available systems be user friendly, intuitive and accommodate for disabilities. In the next section we will outline the advantages and disadvantages of using touch as an input strategy and look at design guidelines for older adult interaction. 


\section{Touch screens versus other pointing devices}

\subsection{Advantages and disadvantages}

One of the most commonly used approaches for evaluating the benefits of touch screen technology is to compare it to existing methods. As briefly mentioned in the previous section, the suitability of the device may depend on the task at hand. For example, direct input devices such as touch screen may be suitable for novice users for point-and-click tasks, and experienced users may find using indirect devices such as a mouse more suitable for tasks requiring extensive keyboard entry (Charness \& Jastrzembski, 2010; Fisk et al., 2009; Rogers et al., 2005). In a study examining the effect of direct and indirect input devices on attentional demand, McLaughlin et al. (2009) found that mismatching the input device to task requires high attentional demand of the users. McLaughlin et al. found that matching the appropriate input device to a particular task (e.g. touch screen for pointing tasks) has considerable benefit for older adults, who experience normal age-related attentional decline. Shneiderman (1991) points out the advantages and disadvantages of touch screens over other input devices. The advantages include:

- Touching a visual display of choices requires little thinking and is a form of direct manipulation that is easy to learn.

- Touch screens are the fastest pointing device.

- Touch screens have easier hand-eye coordination than mice or keyboards.

- No extra workspace is required as with other pointing devices.

- Touch screens are durable in public access and in high-volume usage.

The disadvantages include:

- Users' hands may obscure the screen.

- Screens need to be installed at a lower position and tilted to reduce arm fatigue.

- Some reduction in image brightness may occur.

- They cost more than alternative devices.

Although Shneiderman made these claims 20 years previously, they still apply to today's touch screen technology and the views are more recently echoed by Bhalla and Bhalla (2010). According to research these advantages outweigh the disadvantages for older users. For example, in a study comparing input devices for numeric entry tasks it was found that both younger and older participants preferred using the touch screen compared to physical keypad (Chung et al., 2010). Similarly, Umemuro (2004) showed that anxiety towards computers was reduced significantly for elderly users trained with a touch screen terminal, whereas there was no significant decline in anxiety for those using a keyboard based terminal. In comparison to a computer mouse, using a touch screen can significantly reduce the age effects for the time it takes to carry out pointing tasks (Iwase \& Murata, 2002). Ease of use and reduced anxiety towards technology follow well designed systems and interfaces. In section 3.2 we will discuss some guidelines suggested for touch screen use.

\subsection{Touch screen design guidelines}

The usability website Sap Design Guild put together a comprehensive guide to designing touch screen applications (Waloszek, 2000; http://www.sapdesignguild.org/resources/ 
tsdesigngl/index.htm). In this document they state that there are five golden rules for designing touch screen interfaces. These include:

1. Speed - make sure the application runs fast,

2. Intuitiveness - avoid making the user think about what they need to do,

3. Choices - limit choices,

4. Guidance - guide the user through the application, and

5. Testing - use focus groups or observations to test the application before putting it in the "wild".

In relation to the interface design of touch sensitive displays, Waloszek (2000) also provided some guidance. The main areas that were covered were the screen layout, maintaining screen space, data entry, buttons and menus, and complex controls. We will outline some of the main points here along with other research conducted on these subjects.

\subsubsection{Screen layout}

Some of the factors that impact the experience for touch screen users are the size of the screen, the precision needed to select a target and the design of the screen elements (colour and grouping etc.). With large screens, designers can afford to offer large input and output features. Users should easily see menus and content on the one screen. On smaller screens however, such as mobile phones, there needs to be a compromise between these elements. To investigate just how much of a compromise is needed for older users Ziefle (2010) asked 40 participants between 55 and 73 years of age to take part in a series of navigation tasks. The focus of this work was between the visual density (font size; 8pt compared to 12pt) and preview size (menu; 1 option at a time compared to 5). Overall she found that the preview size had more impact on usability and navigation. Effectiveness and efficiency was lowest when only one menu option was shown on the screen, even with a large font size. The best performance was observed for the display with large font size and large preview.

With touch screen systems, users are not only looking at the screen, they are interacting with it. The layout of target buttons on the screen impacts this interaction. Larger features such as big buttons benefit users with vision problems but they also support accurate target selection. Conversely, decreasing the size of the buttons below finger width reduces performance (Lee \& Zhai, 2009). Fitts (1954) hypothesized that the time needed to move to a target area is a function of the distance to the target and the size of the target. This speed/accuracy trade off is referred to as Fitts's Law and has been applied and modified extensively to assist interface designs such as target size and grouping, pop-up menus, and using the corners of the screen (Sears \& Shneiderman, 1991). Providing large targets is particularly important for older users. Fezzani et al. (2010) looked at the effect of target size on performance for younger and older individuals. The study showed that reducing the target size resulted in difficulties with pointing accuracy, increased the time per task and increased the mental cost associated with performance. For the older users, the impact of motor difficulty on performance was considerable.

When designing the interface you need to consider what you want the user to see, for example, being consistent when grouping elements to aid navigation and eliminating extraneous features so the screen is not cluttered. Colour is also an important variable. For older or colour blind users it is necessary to have high colour contrast. Grouping menus by 
colour alone can also lead to difficulties for these users. Instead it would be preferable to use text, spacing or frames. Regarding the background colour, Waloszek (2000) does not recommend black or dark colours as they highlight finger prints and increase glare. Perhaps this suggestion is more applicable for public touch screen kiosks or applications for larger devices, as it contradicts the popularity of touch screen mobile phone applications such as on Apple's iPhone. It should be noted however that the iPhone offers a reversal of background/foreground colours as an accessibility option for those who want higher colour contrast (http://www.apple.com/accessibility/iphone/vision.html).

\subsubsection{Data entry}

Virtual alphabetic or numeric data entry is not ideal for touch screen users as the virtual keyboard or keypad obscures the screen and the inputting arm can quickly become fatigued. Data entry should be kept to a minimum, however if possible, other options could be offered, such as clicking on predefined values, providing buttons or sliders for increment and decrement values or lastly using a physical keypad or keyboard (Waloszek, 2000). Although there are issues with data entry on touch screens for extensive interaction, virtual data entry may be preferable to users for small data input activities. For example, as mentioned in section 3.1, both younger and older people show a preference for touch screen keypads in numeric entry tasks (Chung et al., 2010). As the virtual keypad is situated on the screen display the user does not have to divide their attention between the entry device and the screen content. This is of particular benefit to older users as there is an age-related decline in divided attention (see section 2.2).

Other types of input that have been considered as an input strategy are speech and eyegaze. However, these forms of input are not commonly associated with touch screen systems. These methods would accommodate motor difficulties associated with ageing such as arthritis or tremble. Developments into these techniques are already underway. For example, Google have recently released an application which allows users to speak actions or search queries into their mobile phone (http://www.google.com/mobile/voiceactions/). However, there are several issues that impede the efficiency of speech input, such as the variation of users' intonation and the effect of external noise. Furthermore, Shneiderman (2000) pointed out in one of his articles "The Limits of Speech Recognition" that people have more difficulty simultaneously thinking and speaking, than they do thinking and walking, or thinking and typing on a keyboard. This is because the part of the brain responsible for problem solving and recall also supports speech.

Eye-gaze may have potential as an input strategy for older users. Murata (2006) examined pointing time and performance of young, middle aged and older individuals when using a mouse and also an eye-tracking system for input. Not surprisingly based on the previous research mentioned, compared to younger users the older adults found the mouse more difficult to use and were the slowest to perform the task. There were less age differences when using the eye-gaze input. Interestingly the younger participants liked the eye-gaze input least. This may be because they were more confident using the mouse. It was noted by the author that issues such as the necessity of calibration existed when using the eye-gaze input and that the technology would need to be further developed before it is considered as an acceptable input strategy. 


\subsubsection{Buttons and menus}

Touch screen applications best afford point and select interaction and buttons are the most appropriate target for this action. The optimal button size for finger selection is believed to be at least 20mm square (Chung et al., 2010; Waloszek, 2000). Strauss (2009) proposed that wider buttons $(20 \mathrm{~mm}$ by $31.75 \mathrm{~mm}$ ) are more appealing to users based on the Golden Ratio Phi (Livio, 2002). Minimum recommended button size is $10 \mathrm{~mm}$ (Lee \& Zhai, 2009) and a slightly larger $11.43 \mathrm{~mm}$ for older users (Jin et al., 2007). Regarding button spacing, Jin et al. recommended that a space between $3.17 \mathrm{~mm}$ and $12.7 \mathrm{~mm}$ is needed to lower performance error rates for older users.

The design elements of buttons, such as text, colour and icons, can either help or hinder users and should be considered carefully (Maguire, 1999). In a review of user guidelines for public touch screen kiosks Maguire reported on the necessity of providing text that users can see and read (such as sans-serif, 16pt), and terms and/or icons that users will recognise. It is also recommended that colour is used to group items together and provide activity feedback but that it should be used sparingly and with colour blind users in mind.

Physical hard buttons have advantages over soft touch screen buttons in that users have direct tactile feedback that the button has been pressed. With soft buttons on a screen, common forms of feedback are visual output such as changing the colour of the button after selection. Audio and haptic feedback, commonly associated with mobile phones, may benefit other forms of touch screen systems. For example, Lee and Zhai (2009) compared the speed and accuracy of users for soft buttons with no feedback, audio feedback, haptic (vibration) feedback, and both audio and haptic together. They found that having either audio or haptic significantly improved performance over having no feedback. There was no further increase for having both forms together however.

Menus provide a way for users to navigate a system. We mentioned previously that users perform better when they are displayed a large menu preview (Ziefle, 2010), or in other words, when they can see all their menu options. Maguire (1999) supports this finding stating that where possible all menu items should be displayed on the one page. Waloszek (2000) advises that different menu groups (e.g. main menu and secondary menu) should be differentiated by their shape and style.

\subsubsection{Complex controls}

Complex controls for touch screen applications include the use of lists and tables (Waloszek, 2000), which may be more suitable for high precision input such as a computer mouse. On standard PC's, scroll bars are typically used if the information extends beyond the screen size. However, scroll bars are not suited to touch screen interaction, and older users find them particularly difficult to use. Dickinson et al. (2010) carried out an 11 week study examining the barriers older people experience when learning to use computers. Some of the problems people found most difficult included double clicking the mouse and using scroll bars. As the researchers had ensured that all targets and icons were enlarged, there were no problems with precision or seeing objects on the screen. Features such as double tapping and scroll bars should be avoided for touch screen use to accommodate older users. 
Other options to view an extended screen could be incorporating next/previous or up/down buttons, or using gestures such as swiping the screen horizontally or vertically, depending on the navigation structure. Swiping gestures are common forms of input for smaller touch screen systems such as mobile phone or tablets where the user can swipe their index finger from one side of the screen to another to change the page. Larger surfaces would require more physical effort for this task to be achieved. Familiar gestures such as using a finger or stylus in a crossing off motion $(X)$ to delete an item or ticking $(\checkmark)$ to save an item are particularly compatible for older users learning this input strategy (Stöbel, 2009).

\subsection{Designing for disability}

The purpose of this chapter is to discuss the accessibility of touch screen technology for older users and to review the recommendations for designing touch screen interfaces. This is with the assumption that both able-bodied users and users with impairments can benefit from touch screen devices like mobile phones, tablets and public kiosks. Newell (2008) argues however that the concept of "design for all" is unrealistic as there are distinctions between mainstream technology and assistive technology (including rehabilitative devices). Newell outlines some of the factors that should be considered when designing for users with a disability:

- Much greater variety of user characteristics and functionality.

- The difficulty in finding and recruiting "representative users".

- Possible conflict of interest between accessibility for people with difference types of disability.

- Conflicts between accessibility, and ease of use for less disabled people.

- Situations were "design for all" is certainly not appropriate (e.g. blind drivers of motor cars)

- The need to specify exactly the characteristics and functionality of the user group.

- Provision of accessibility via the provision of additional components.

Although Newell makes the point that users with disabilities have specific needs when it comes to technology, he points out that the aesthetics of a device are just as important as its functionality (Newell, 2003; Newell, 2008). He reasons that assistive technology could look more like the aesthetically pleasing mainstream technology if developers were motivated enough. There has been some improvement over the last few years suggesting that developers are listening to their users. For example, current hearing aids are much more discrete compared to past designs.

Often, older and disabled users come under the same category as both groups tend to have one or more perceptual, cognitive or physical disabilities. In the previous section we have discussed the design needs of older users in relation to target size and spacing etc. but it is interesting to consider whether users with disabilities have similar needs. To answer this question, Irwin and Sesto (2009) examined the performance of people with and without motor control disabilities on a touch screen device. Of the 30 participants in the study, there were 11 with Cerebral Palsy, 11 with Multiple Sclerosis and 8 age matched controls. Performance levels were based on timing and accuracy using buttons ranging in size from $10 \mathrm{~mm}$ square to $30 \mathrm{~mm}$ square, with spacing ranging between $1 \mathrm{~mm}$ and $3 \mathrm{~mm}$. Similar to older users, the optimum button size for the participants in this study was between 20 and 
$25 \mathrm{~mm}$. There was a $23 \%$ reduction in performance time for buttons at size $25 \mathrm{~mm}$ and error rates began to level off for buttons with size $20 \mathrm{~mm}$. If the screen size is large enough, designers could easily accommodate for disabled users by implementing these features in application interfaces or at the very least implementing the option to adjust settings to increase accessibility.

Mobile touch screen interfaces are more challenging due to the limited screen space. Besides the applications installed in touch screen mobile phones, there are many usability benefits for people with motor impairments. For example, the soft buttons support users with low muscle strength and the phone itself can be easily carried and used in one hand. Touch screens devices afford many types of user input. Users can tap the screen to select a target, swipe across the screen to view up or down a page, and they can resize the screen by pinching or releasing their fingers on the screen surface. Guerreiro et al. (2010) evaluated touch techniques with a group of tetraplegic participants. They looked at the techniques of tapping, crossing (swiping), exiting (swiping the edge or corners to leave the screen) and directional gesturing (swiping in a particular direction). The participants were asked to complete tasks using these input gestures. The size and position of targets were also under scrutiny. There were several interesting observations from this study. Firstly there was little difference in performance between the medium $(12 \mathrm{~mm})$ and large $(17 \mathrm{~mm})$ target size. There was a significantly higher error rate for the smallest targets $(7 \mathrm{~mm})$, supporting Lee \& Zhai's (2009) finding that using a target size below $10 \mathrm{~mm}$ decreases performance. The position of a target (corner, edge or middle of the screen) did not affect performance however the authors suggest that using corners and edges allow participants to tap targets more precisely. The exiting gesture proved to be the most difficult whereas tapping and crossing gestures produced higher performance levels. These findings should give designers some insight into appropriate target design and gesture input for motor impaired users.

Touch screen devices do not offer the tactile feedback that people with visual impairments rely on with physical objects, like a keyboard or telephone keys. Screen readers provide blind and visually impaired computer users access to information on their screen. VoiceOver is an application available on the iPhone which tells the user what item they are currently touching (http://www.apple.com/accessibility/iphone/vision.html). The speed of the voice over can be adjusted depending on the users preference and other phone related sounds are automatically lowered when the voice over is activated. There is no doubt that this application is a useful one. Bonner et al. (2010) evaluated the usability of iPhone's VoiceOver text entry system compared with an eyes-free technique that they developed called No-Look Notes. The aim of the No-Look Notes technique was to provide a text entry system for blind users that was robust, had a familiar layout and allowed users to painlessly explore the system's layout. Keyboard characters are arranged in an 8 segment pie menu from which the user can select one segment (e.g. ABC) (see figure 3). This brings them to the secondary screen where they can select their letter of choice (e.g. A). Different gestures, such as resting a finger on a segment and tapping a second finger, are used to allow the user to both explore and select with their fingers. The authors noted that they did not integrate haptic (vibration) feedback into the system as this may not be available on all mobile phones. Visual and auditory feedback were included however. An iPhone was used to evaluate both text entry techniques, VoiceOver and No-Look Notes. A group of 10 visually impaired participants were asked to use both systems for one hour (after 15 minutes practice), inputting words from a predefined list. Performance was measured based on entry 
speed and accuracy. A questionnaire was also given at the end of each session to obtain subjective feedback. Nearly all of the participants (90\%) performed significantly faster using the No-Look Notes system and error rates were lower. Although participants were enthusiastic about both techniques, they rated the No-Look Notes as easier to use and learn.
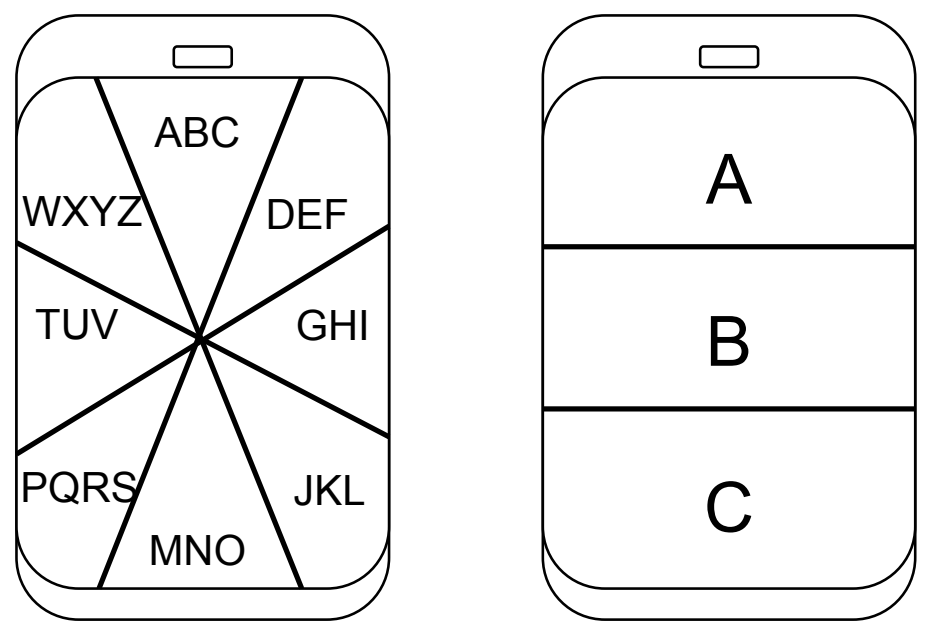

Fig. 3. Structure of touch screen keyboard for No-Look-Notes (Bonner et al., (2010); Left image shows the main screen from which the user selects a letter grouping. This allows them to then choose a specific letter, as shown on the right.

Raman and Chen (2010) at Google also created a method for eyes-free gesture input on a touch screen mobile phone. This method was designed to support people to accurately enter characters without having to see the screen. Instead of the users trying to find the correct character, wherever they touch on the screen becomes 5 . The user can then swipe in different directions to enter further numbers, up for 2, down for 8 etc. The input is also supported by visual, auditory and haptic feedback. Having multiple forms of feedback like this is useful for users of all abilities to compensate for noise or distractions in the environment.

In this section we have outlined some of the design recommendations for touch screens put forward by researchers and designers in the field. Adhering to these guidelines is particularly important for older and disabled users who may have perceptual, cognitive, and physical difficulties.

\section{Touch screen applications}

We have touched on some of the research which highlighted the benefit of touch screens for older users compared with other input devices. It is because of these advantages that touch screen technology is so frequently used for general public use. The following are only some of the applications of touch screens. 


\subsection{Public environments}

Public information displays must cater for the largest possible target group, including the young, old, disabled and non-native. Public touch screen kiosks include airport self-check in, supermarket self-checkout, tourism information points, public transport ticket dispensers and many more. In many retail establishments staff also use touch screen devices. To accommodate the broad range of users these public touch screens tend to have large screen displays at a low height or with a tilted screen. The interface usually displays large target options with a combination of image and text, along with short concise instructions (see figure 4 for example). This allows for information to become easily and quickly accessible for users only requiring finger-touch interaction.

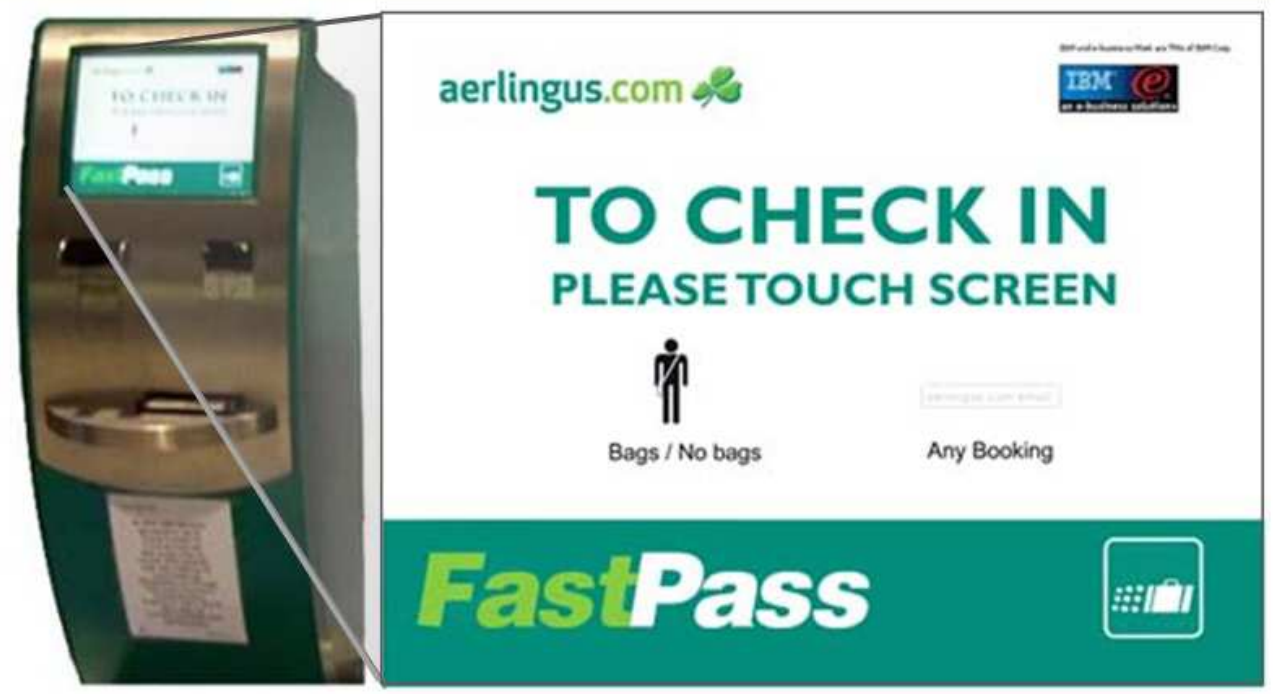

Fig. 4. Airport check-in kiosk; The interface makes use of large, short instructions and combines text labels with images for target options, supporting non-English speaking users.

In order for touch screen kiosks to be attractive to the public, it should be quicker and easier to use this system compared to a person serviced desk. This is not always the case however. In supermarkets for example, self-checkout systems are often a cause of frustration for customers (Smith, 2010). Although the self-checkout can be quicker for customers with a small number of items, often the attention of staff is needed to verify the age of a customer buying alcohol, to remove security tags or if there are any errors messages. Until a more efficient system is put into place for shoppers it is likely that the preference of customers will remain with manned tills. Public kiosks also have to take into account the context of where it will be used. The location of public kiosks needs to be conspicuous so that people will notice and use them. Applications need to be very easy to use to accommodate for the busy and noisy environments where they are situated, such as supermarkets and airports. The scenario of desperately trying to figure out how to use a self-service system while a queue forms behind you is familiar for many people, young and old. The pressure is amplified if the people in the queue are in a hurry, for example to catch the next train or 
flight. It is also particularly important that users feel competent interacting with systems such as ATMs that might require the input and output of private information. Systems such as these can be placed in a secluded area such as a booth, so that users feel more secure about entering sensitive information in a public place. This can also help to reduce the exposure to noise and other distractions.

\subsection{Home environments}

The integration of touch screen systems into the home environment has been somewhat slower compared to public and mobile phone touch screen use. The popularity of tablet computers, coupled with the advances made in sensor network monitoring, has encouraged the development of a series of applications based on home living. For example, the home security company uContol recently released a touch screen system which can be placed in the user's home allowing them to monitor and control the security status of the house (http://www.youcontrol.com/touchscreen.html). Another example of home monitoring is in relation to energy consumption displays. Such prototypes include home energy systems developed by Intel (cited in Eisenberg, 2010) and CLARITY (see figure 6; Doherty et al., 2010).

Researchers and manufacturers have taken note of this touch screen "revolution" and it might not be long before we see touch sensitive displays embedded in many of our home appliances. For example, Gorenje introduced the iChef, an oven with a large touch screen colour display, where the user can choose different functions such as the temperature, timer control etc. (http://www.gorenjegroup.com/en/livingkitchen2011-pressroom/ichefrevolutionary-oven-touch-control). Similarly, Luo, Jin, and Li (2009) proposed the concept of a "smart fridge" which consisted of a touch screen display integrated into the door of a fridge. The purpose was to offer nutritional and recipe advice based on the food contained in the fridge.

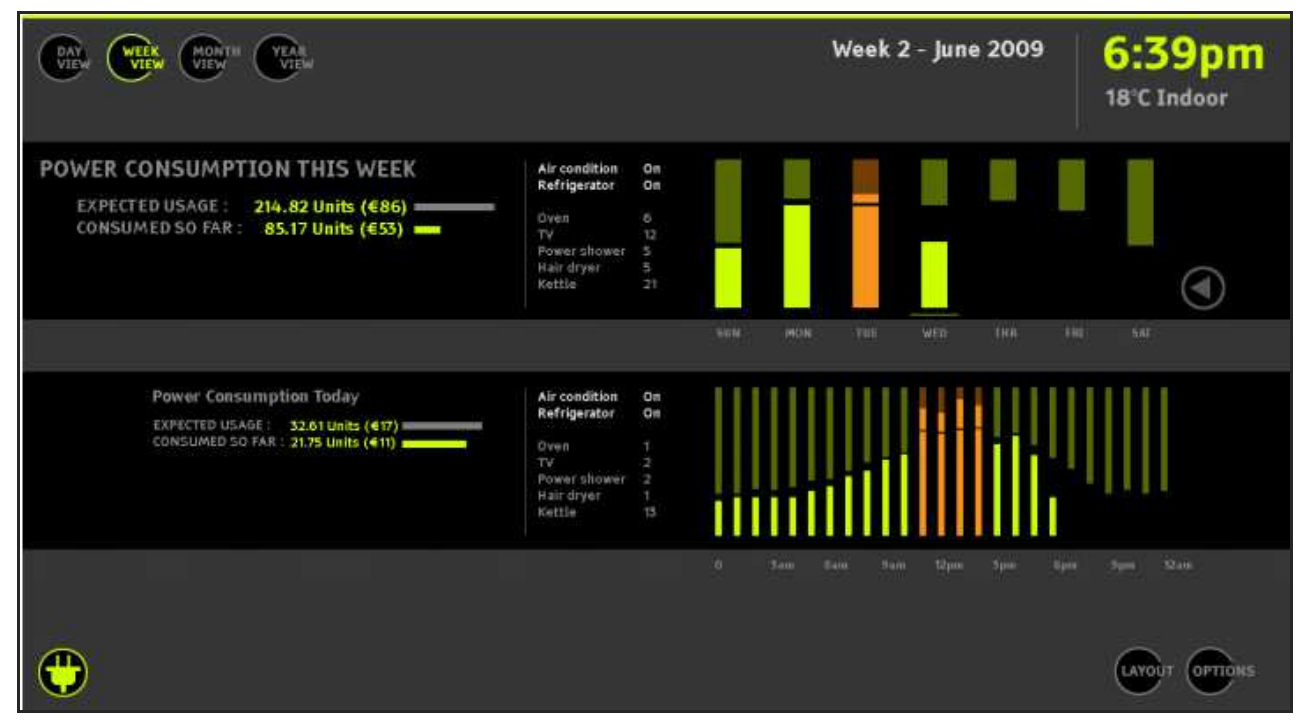

Fig. 5. Example of dark background with bright information; In-home display electricity monitor, Doherty et al. (2010). 
It is worth noting that all of the touch screen interfaces mentioned in this section have one similar design characteristic; the colour scheme. In all of these interfaces a dark grey and black background is used, with important information highlighted in a bright colour and less pertinent information displayed in a light grey colour (see figure 5 for example). A reason for this display option is given by Doherty et al. (2010). They explain that having a dark background and bright information allows the display to be seen in a bright or darkly lit room. For example, a bedside digital clock can be easily read in a dark room, however if the background display was white it would momentarily blind the sleepy individual.

There are obvious benefits to applications such as the ones just mentioned, including security, and awareness of energy consumption etc. However it is not only the usefulness and usability of the device that is significant. Factors such as the cost of the device, the Internet connection and the subscription to the company monitoring the home have to be considered, particularly in the context of older users who may not have a regular income. These issues may not be a problem in the future if technology costs are reduced and applications like the ones mentioned above come as a standard feature of household security and electricity services.

\subsection{Healthcare environments}

There has been extensive research carried out looking at the use of touch screens in medical environments. This may be due to the busy nature of hospitals and medical centres where staff cannot always provide patients with the amount of time they would like. Medical centres such as the Summer Town Health Centre in Oxford, UK, have installed a touch screen arrival system for patients to register their information before an appointment. Other applications include touch screen way-finding kiosks in hospitals (Wright et al., 2010), medication management applications (Siek et al., 2011), and self-health status assessment (Yost et al., 2010).

Many studies using touch screen kiosks do not assess participants' subjective opinions about the touch screen technology, concentrating more on the applications installed. Wright et al. (2010) for example noted that during their ethnographic study of a hospital way-finding touch screen kiosk, it was impractical to interview visitors as they were in a hurry to get to their destination. Other studies were able to obtain feedback however. For instance, Nicolas et al. (2003) found that a third of people using a touch screen health information kiosk found it difficult to use compared to only $23 \%$ of Internet users. They believed that the kiosk users were less computer literate and therefore less familiar with the computer terms such as "prev screen" used in the application. This highlights the importance of following design guidelines to support users of all levels. In contrast to this finding, Allenby et al. (2002) looked at the use of touch screen technology for obtaining self-report information from 450 cancer patients. The touch screen systems were placed in cubicles to support patient privacy. Accessibility was accommodated for patients in wheelchairs or confined to a bed by providing mobile touch screen systems. An assistance button was also included on the screen so that users could call a nurse if they needed help. After the participants completed the touch screen self reports, they were asked to fill in a questionnaire regarding touch screen acceptability. Overall, $99 \%$ of the participants found the touch screen easy to use and over half of these had never used a computer before. 
Way-finding in hospital buildings can be challenging for visitors. This may be because of the large size of the buildings and the division into clinical departments and wards. The state of mind of the person visiting the hospital should also be taken into account, as it is likely they will be upset or in a hurry to find their sick friend or relative. To compensate for this problem, Wright et al. (2010) developed a touch screen kiosk for visitors to retrieve wayfinding information. Particular attention was paid to the accessibility of the kiosk. This was in relation to the physical structure, the interface and the information output. For example, the kiosk was put at wheelchair height at a slant so that standing users would be able to use it easily. The interface consisted of a limited number of large targets, an audio output option and an animated map with a photograph of the destination. Users were also provided with the option to find wheelchair friendly routes avoiding staircases. Wright et al. carried out a field study over 10 weeks to evaluate the usefulness of this system. During this time they followed 22 visitors who used the kiosk and they found that 19 of the 22 successfully reached their destination without further help. However, hospital staff reported that after using the system visitors often asked for further way-finding information at the reception desk. Feedback concerning the usability of the system could not be obtained as the users were in a hurry to find their destination; therefore, it was unclear whether the users had difficulty using the touch screen kiosk itself or whether they were looking for reassurance about the directions given.

Health care systems do not have to be limited to hospital or health-based information. Bedside patients can also benefit from touch screen applications to entertain them and alleviate boredom. An example of this is MEDIVista, an innovative computing platform developed by an Irish bedside computing and media solutions company, Lincor Solutions (Murphy \& O'Donnell, 2010). MEDIVista is an information management and entertainment system placed at a patient's hospital bedside. The terminal comprises of a touch screen and telephone mounted on a swivel arm for easy patient access. The patient information system consists of electronic hospital information, patient records, meal ordering, and employee tracking. The entertainment system comprises of a television, radio, Internet, audio books, online shopping, games, and films on demand. Nearly 20,000 of these systems are currently installed in hospitals situated in Europe, North America and Asia Pacific. The widespread distribution of MEDIVista suggests that it is a well received application by both hospital staff and patients.

Touch screen applications in health care settings can be a valuable time saver for staff or a source of entertainment for patients. The key factors that need to be taken into account for these applications are (1) accessibility - in a hospital setting it is likely that users will not have full physical abilities or may be wheelchair or bed bound, (2) knowledge of computer terms - users, particularly older people, may have never used a computer before and would not be familiar with computer-related terms, and (3) knowledge of health terms - users may not be familiar with medical terminology, therefore they should be explained clearly. From the studies outlined above it is clear that although touch screen systems can support hospital patients and visitors up to a point, most often people in healthcare environments need comfort and advice along with medical information that only humans can provide.

\subsection{Communication and social devices}

Communication devices such as mobile phones are probably the most popular touch screen for social use. However, research has shown that older adults are less likely to use mobile 
phones than younger adults (Cullen et al., 2008). Kurniawan (2008) examined older adults' mobile phone use and found that it was mostly limited to basic functions such as making calls and sending text messages. In this study, older participants claimed that the design of mobile phones, such as the size of screen features, inhibited their use of the device. The mobile phones discussed in these studies were not touch screen enabled, however the issues raised are common problems and can be applied generally.

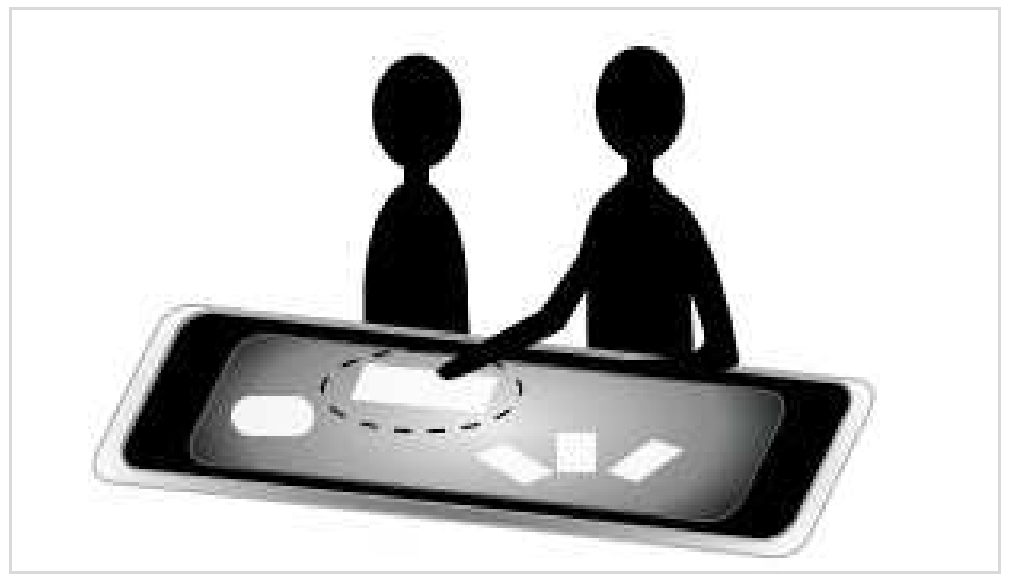

Fig. 6. Multi-touch screen tabletops allow multiple users to interact with the data on display.

Novel applications have been developed for mobile phones to encourage social interaction of multiple users with the one device. A storybook application, StoryKit, was designed for the Apple iPhone (Quinn et al., 2009). With this application story books are created by inputting text, illustrations, audio recordings and photographs into the device. The purpose of this was to promote adult guided learning, encouraging grandparents and grandchildren to work together to create stories on the mobile phone. Although the creative and social aspect of the application was well liked by both older and younger users, some older users reported difficulty using intricate iPhone features such as the touch screen keyboard. Although using a touch screen phone as a platform for socially interactive applications supports the mobile aspect of using features in the environment to build a story, larger screen sizes may be more suitable for multi-person usage.

An example of a social interaction system on the opposite end of the size scale is Sharetouch (Tsai et al., 2011), a multi-touch tabletop (see figure 6). The purpose of this system is to act as a coffee table and share-display system in one, so that older adults in senior centres can communicate with others, share data, or play games. Other systems have been designed to support reminiscence between older adults and their family, friends or caregivers. The CIRCA reminiscence system was designed to support communication and reminiscence between older adults with dementia and their carers (Astel et al., 2010). The system is a touch screen device that allows users to explore a set of text, photographs, sound recordings and film recordings. These media items act as a trigger for discussion and allow the older user control over the discussion topic. Astel et al. found that interacting with the CIRCA system increased the level of eye contact and intimacy between older participant and their carer. 
Touch screen technology could also support older adults' lifelogging activities. Lifelogging is automatically recording activities and events in one's life and is now becoming more and more possible with sensors such as accelerometers (recording movement), Bluetooth (identifying the people around you) and cameras (capturing a visual record) being

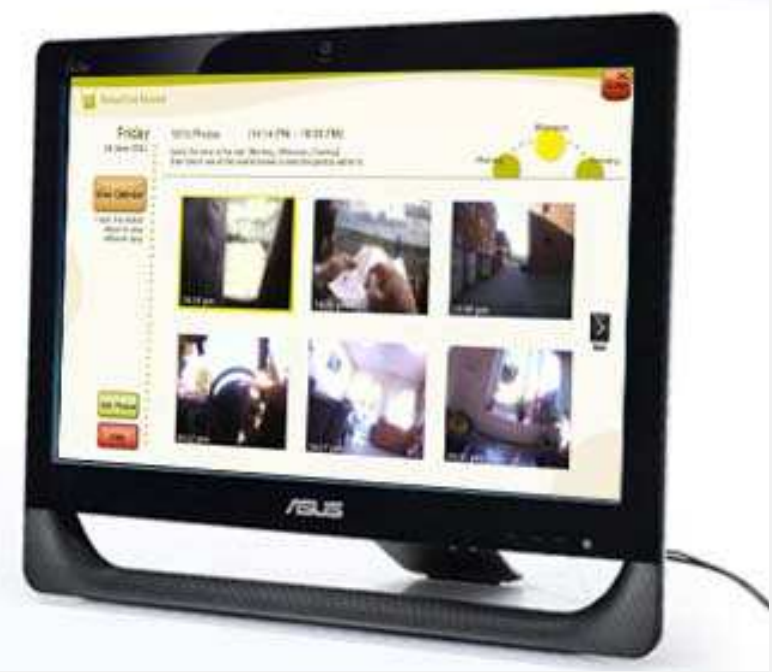

Fig. 7. Touch screen to support older adults browsing through lifelog images (Caprani et al., 2010).

integrated into everyday devices like mobile phones. Recording all this information can provide people with a rich collection of information about what they did, where they were and who they were with. Even after only a year, a person could collect millions of files and presenting this vast amount of data in a manageable way is challenging. However researchers have come up with methods to do this, such as segmenting the information into separate events or activities (Doherty, 2009). Using this segmentation method, Caprani et al. (2010) designed a touch screen browser for older users to upload and view lifelog images (see figure 7). Older participants were involved throughout the design process, advising features such as text and image size, colour contrast and labelling terms. Each image on the main screen represents an event. An event is a group of images related to one activity like eating lunch or doing the crossword. A field study was conducted over a period of two weeks to evaluate the usability of the browser with a small sample of older adults with no computer experience. Although there were initial difficulties learning to turn on and off the computer and double tapping to open the browser, overall the participants felt comfortable using the touch screen. They also reported feeling more confident towards computers and enjoyed interacting with it. It has been shown that lifelog collections can support recall for people with memory impairments (Berry et al., 2009). Therefore a lifetime of data representing our activities could support our memory as we grow older. Until then, other motivations for capturing visual lifelogs could be to support reminiscence by sharing and exchanging these photographs with family (Caprani et al., 2011) or using the data to create narratives of events that we experienced in our life (Byrne et al., 2011). 
The purpose of social and communication devices is to encourage individuals to interact with each other through a medium. Touch screen devices offer older users with limited computer experience access to this. In the examples outlined above, the ease of use of the systems allowed the older users to take control of their own activities and conversations with others. Communication technology can help to alleviate the feeling of isolation and loneliness that many older adults experience by providing them access to friends and family. This may be through phone or video calls, email or data sharing.

\section{Conclusion}

Shneiderman's prediction in 1991 that touch screen technology would become ubiquitous has proven to be an acutely accurate one. We have discussed in this chapter the progress that has been made since touch screens were first conceptualised by E.A. Johnson in 1965. Now touch screen technology is used in public, healthcare, and home environments, and the commercial market has greatly profited from the popularity of touch screen mobile phones and tablet computers. But it is the intuitive nature of direct finger input that makes touch screen technology so appealing to users of all ages and abilities.

An increase in longevity together with declines in birth-rate has resulted in an ageing population and developers have come to realise that older adults will soon be a major user market. Technology is becoming easier to use and many systems incorporate accessibility features to support users with impairments. Research has shown that older adults perform better and prefer using touch screens compared to other input devices. There is also less of an age-related difference in performance when using touch technology. Having said this there is still some way to go before mainstream technology can fully accommodate for the needs of older and disabled users. However, as we can see from the research outlined in this chapter, there has been extensive work carried out investigating optimum design features for touch screen systems to support older and disabled users. These have included button size and spacing, menu structures, and data entry among others. Although other forms of input such as eye-gaze or indeed the computer mouse may become more usable for older adults in the future, touch screens provide an accessible alternative. By following the guidelines and recommendations put forward by researchers in this field it should now be possible to design applications that are functional, accessible and aesthetically beautiful.

\section{Acknowledgements}

The funding for this research has been provided by the Irish Research Council for Science, Engineering and Technology. This work is also supported by Science Foundation Ireland under grant $07 / \mathrm{CE} / \mathrm{I} 1147$.

\section{References}

Allenby, A., Mathews, J., Beresford, J., \& McLachlan, S.A. (2002). The Application of Computer Touch-Screen Technology for Psychosocial Distress in an Ambulatory Oncology Setting. European Journal of Cancer Care, Vol.11, No.4, (December 2002), pp. $245-253$

Astell, A.J., Ellis, M.P., Bernardi, L., Alm, N., Dye, R., Gowans, G., \& Campbell, J. (2010). Using a Touch Screen Computer to Support Relationships between People with 
Dementia and Caregivers. Interacting with Computers, Vol.22, (July, 2010), pp. 267275, ISSN 0953-5438

Berry, E., Hampshire, A, Rowe, J., Hodges, S., Kapur, N., Watson, P., Browne, G., Smyth, G., Wood, K. \& Owen, A. (2009). The Neural Basis of Effective Memory Therapy in a Patient with Limbic Encephalitis. Journal of Neurology, Neurosurgery, and Psychiatry with Practical Neurology, Vol.80, No.11, (November 2009), pp. 1202-1205

Bhalla, M.R., \& Bhalla, A.V. (2010). Comparative Study of Various Touchscreen Technologies. International Journal of Computer Applications, Vol.6, No.8, (September 2010), pp. 12-18, ISSN 09758887

Bonner, M.N., Brudvik, J.T., Abowd, G.D., \& Edwards, W.K. (2010). No-Look Notes: Accessible Eyes-Free Multi-Touch Text Entry, Proceedings of Pervasive Computing 2010, pp. 409-426, ISBN 978-3-642-12653-6, Helsinki, Finland, May 17-20, 2010

Bosman, E.A. \& Charness, N. (1996). Age Differences in Skilled Performance and Skill Acquisition, In: Perspectives on Cognitive Change in Adulthood and Aging, T. Hess \& F. Blanchard-Fields, 428-453. McGraw-Hill, ISBN 0070284504, New York

Bouwhuis, D.G. (2003). Design For Person-Environment Interaction in Older Age: A Gerontechnological Perspective. Gerontechnology, Vol.2, No.3, (March 2003), pp. 232-246

Brown, D., Steinbacher, C., Turpin, T., Butler, R., \& Bales, C. (2011). History of Elo, In: Elo TouchSystems, 26.05.2011. Available from http://www.elotouch.com/AboutElo/History/default.asp

Byrne, D., Kelliher, A., \& Jones, G. (2011). Life Editing: Third-Party Perspectives on Lifelog Content, Proceedings of Human Factors in Computing Systems (CHI '11), pp. 15011510, ISBN 978-1-4503-0228-9, Canada, May 7-12, 2011

Caprani, N., Doherty, A.R., Lee, H., Smeaton, A.F., O'Connor, N.E., \& Gurrin, C. (2010). Designing a Touch-Screen SenseCam Browser to Support an Aging Population, Proceedings Human Factors in Computing Systems (CHI EA '10), pp. 4291-4296, ISBN 978-1-60558-930-5, Atlanta, USA, April 10-15, 2010

Caprani, N., O'Connor, N.E., \& Gurrin, C. (2011). Motivating Lifelogging Practices through Shared Family Reminiscence, Proceedings of Human Factors in Computing Systems (CHI EA'11), pp. 10-15, ISBN 978-1-4503-0268-5, Vancouver, Canada, May 7-12, 2011

Charness, N. \& Boot, W.R. (2009). Aging and Information Technology Use: Potential and Barriers. Current Directions in Psychological Science, Vol.18, No. 5, (October, 2009), pp. 253-258, ISSN 09637214

Charness, N., \& Jastrzembski, T.S. (2009). Gerontechnology, In: Future interaction design II, P. Saariluoma \& H. Isomaki (Eds.), 1-29, Springer-Verlag, ISBN 978-1-84800-300-2, London

Chung, M.K., Kim, D., Na, S., \& Lee, D. (2010). Usability Evaluation of Numeric Entry Tasks on Keypad Type and Age. International Journal of Industrial Ergonomics, Vol.40, No.1, (January 2010), pp. 97-105, ISSN 0169-8141

Coleman, G.W., Gibson, L., Hanson, V.L., Bobrowicz, A., \& McKay, A. (2010). Engaging the Disengaged: How Do We Design Technology for Digitally Excluded Older Adults? Proceedings of Designing Interactive Systems (DIS '10), pp. 175-178, ISBN 978-1-45030103-9, Denmark, August 16-20, 2010 
Cullen, K., Dolphin, C., Delaney, S., \& Fitzpatrick, M. (2008). Survey of Older People and ICTs in Ireland, In: Age Action, 27.04.2010, Available from:

www.ageaction.ie/userfiles/.../survey-of-older-people-andicts-in-ireland.pdf

Czaja, S.J. \& Lee, C.C. (2007). Information Technology and Older Adults, In: HumanComputer Interaction Handbook: Fundamentals, Evolving Technologies and Emerging Applications (2nd Edition), A. Sears \& J. A. Jacko, 777-792, Erlbaum, ISBN 0805858709, New Jersey, USA

Czaja, S.J., Charness, N., Fisk, A.D., Hertzog, C., Nair, S.N., Rogers, W.A., \& Sharit, J. (2006). Factors Predicting the Use of Technology: Findings from the Center for Research and Education on Aging and Technology Enhancement (CREATE). Psychology and Aging, Vol. 21, No.2, (June 2006), pp. 333-352

Dickinson, A., Eisma, R., \& Gregor, P. (2010). The Barriers that Older Novices Encounter to Computer Use. Universal Access in the Information Society, Vol.10, No.3, (September 2010), pp. 261-266

Doherty, A.R. (2009). Providing Effective Memory Retrieval Cues through Automatic Structuring and Augmentation of a Lifelog of Images. Unpublished doctoral dissertation, Dublin City University, Dublin, Ireland

Doherty, A.D., Qiu, Z., Foley, C., Lee, H., Gurrin, C., \& Smeaton, A.F. (2010). Green Multimedia: Informing People Of Their Carbon Footprint Through Two Simple Sensors. Proceedings of Multimedia (MM '10), pp. 441-450, ISBN 978-1-60558-933-6, Firenze, Italy, October 25-29, 2010

Eisenberg, A. (February 2010). Energy Scoreboards, Designed for the Home, In: The New York Times, 17.07.2011. Available from http:/ / www.nytimes.com/2010/02/28/business/28novel.html

Fezzani, K., Albinet, C., Thon, B., \& Marquie, J. (2010). The Effect of Motor Difficulty on the Acquisition of a Computer Task: A Comparison between Young and Older Adults. Behaviour E Information Technology, Vol. 29, No.2, (March 2010), pp. 115-124

Fisk, A., Rogers, W.A., Charness, N., Czaja, S.J., \& Sharit, J. (2009). Designing for Older Adults: Principles and Creative Human Factors Approaches (2nd Edition), CRC Press, ISBN 978-1420080551, New York

Fitts, P.M. (1954). The information capacity of the human motor system in controlling the amplitude of movement. Journal of Experimental Psychology, Vol. 47, No. 6, (June 1954), pp. 381-391

Guerreiro, T., Nicolau, H., Jorge, J., \& Gonçalves, D. (2010). Towards Accessible Touch Interfaces, Proceedings of ACM SIGACCESS conference on Computers and Accessibility (ASSETS '10), pp. 19-26, ISBN 978-1-60558-881-0, Orlando, Florida, October 25-27, 2010

Hawthorn, D. (2000). Possible Implications of Aging for Interface Designers. Interacting with Computers, Vol.12, No.5, (April 2000), pp. 507-528

Irwin, C.B., \& Sesto, M.E. (2009). Timing and Accuracy of Individuals With and Without Motor Control Disabilities Completing a Touch Screen Task, Proceedings of Universal Access in Human-Computer Interaction (UAHCI '09), pp. 535 - 536, ISBN 978-3-64202709-3, Calafornia, USA, July 19-24, 2009

Iwase, H., \& Murata, A. (2002). Empirical Study on the Improvement of Usability for TouchPanel for Elderly: Comparison of Usability between Touch-Panel and Mouse, 
Proceedings of Systems, Man and Cybernetics, pp. 252 - 257, ISBN 0-7803-7437-1, Hammamet, Tunisia, October 6-9, 2002

Jay, G.M., \& Willis, S.L. (1992). Influence of Direct Computer Experience on Older Adults' Attitudes towards Computers. Journal of Gerontology: Psychological Sciences, Vol.47, No.4, (July 1992), pp. 250-257

Jin, Z.X., Plocher, T., \&. Kiff, L. (2007). Touch Screen User Interfaces for Older Adults: Button Size And Spacing, Proceedings of Universal Access in Human Computer Interaction: Coping with Diversity (UAHCI '07), pp. 933-941, ISBN 978-3-540-73278-5, Beijing, China, July 22-27, 2007

Johnson, E.A. (1965). Touch Display: A Novel Input/Output Device for Computers. Electronics Letters, Vol.1, No.8, (October 1965), pp. 219-220

Kester, J.D., Benjamin, A.S., Castel, A.D., \& Craik, F.I.M. (2002). Memory in Elderly People, In: The Handbook of Memory Disorders, A.D. Baddely, M.D. Kopelman, B.A. Wilson (Eds.), 543-568, Wiley, ISBN 047149819X, London

Kurniawan, S. (2008). Older people and Mobile Phones: A Multi-Method Investigation. International Journal of Human-Computer Studies, Vol.66, No. 12, (December 2008), pp. 889-901, ISSN 1071-5819

Lee, S., \& Zhai, S. (2009). The Performance of Touch Screen Soft Buttons, Proceedings of Human Factors in Computing Systems (CHI '09), pp.309-318, ISBN 978-1-60558-246-7, Boston, USA, April 4-9, 2009

Livio, M. (2002). The Golden Ratio: The Story of Phi, the World's Most Astonishing Number. Broadway Books, ISBN 0-7679-0815-5, New York, USA

Luo, S., Jin, J.S. \& Li, J. (2009). A Smart Fridge With an Ability to Enhance Health and Enable Better Nutrition. International Journal of Multimedia and Ubiquitous Engineering, Vol.4, No.2 (April 2009), pp. 69-80

Maguire, M.C. (1999). A Review of User-Interface Design Guidelines for Public Information Kiosk Systems. International Journal of Human-Computer Studies, Vol.50, No.3, (March 1999), pp.263-286

Mamolo M., \& Scherbov S. (2009). Population Projections for Forty-Four European Countries: The Ongoing Population Ageing. In: European Demographic Research Papers, 02.08.2011, Available from http://www.oeaw.ac.at/vid/download/edrp_2_09.pdf

McLaughlin, A.C., Rogers, W.A., \& Fisk, A.D. (2009). Using Direct and Indirect Devices: Attention Demands and Are-Related Differences. ACM Transactions on ComputerHuman Interaction, Vol.16, No.1, (April 2009), pp.1-15

Mitzner, T.L., Boron, J.B., Fausset, C.B., Adams, A.E., Charness, N., Czaja, S. J., Dijkstra, K., et al. (2010). Older Adults Talk Technology: Technology Usage and Attitudes. Computers in Human Behavior, Vol.26, No.6, (November 2010), pp.1710-1721, ISSN 07475632

Morris, A., Goodman, J., \& Brading, H. (2007). Internet Use and Non-Use: Views of Older Users. Universal Access in the Information Society, Vol.6, No.1, (May 2007), pp. 43-57, ISSN 16155289

Murata, A. (2006). Eye-Gaze Input versus Mouse: Cursor Control as a Function of Age. International Journal of Human-Computer Interaction, Vol.21, No.1, (January 2006), pp. 1-14, ISSN 10447318 
Murphy, E., \& O’Donnell, P. (2010). U.S. Patent No. 0017437. Washington, DC: U.S. Parent and Trademark Office

Newell, A. (2003). Inclusive Design or Assistive Technology, In: Inclusive Design - Design for the Whole Population, J. Clarkson, S. Keates, \& C. Lebbon (Eds.), 172-181, Springer, ISBN 978-1852337001, London

Newell, A. (2008). User Sensitive Design for Older and Disabled People, In: Technology for Aging, Disability and Independence: Computer and Engineering Design and Applications, A. Helal, M. Mokhtari, B. Abdulrazak (Eds.), 787-802, John Wiley \& Sons, Inc, ISBN 9780471711551, New Jersey

Nicolas, D., Huntington, P., \& Williams, P. (2003). Delivering Consumer Health Information Digitally: A Comparison Between the Web and Touchscreen Kiosk. Journal of Medical Systems, Vol.27, No.1, (February 2003), pp. 13-34

Quinn, A. J., Bederson, B. B., Bonsignore, E. M., Druin, A. (2009). Storykit: Designing a Mobile Application for Story Creation by Children and Older Adults, In: Technical Report HCIL-2009-22, 01.08.2011, Available from http://hcil.cs.umd.edu/trs/200922/2009-22.pdf

Raman, T.V., \& Chen, C.L. (2010). U.S. Patent No. 0073329. Minneapolis, MN: U.S. Patent and Trademark Office

Rogers, W.A., Fisk, A.D., McLaughlin, A.C., \& Pak, R. (2005). Touch a Screen or Turn a Knob: Choosing the Best Device for the Job. Human Factors, Vol.47, No.2, (June 2005), pp. 271-88

Sears, A., \& Shneiderman, B. (1991). High Precision Touchscreens: Design Strategies and Comparisons with a Mouse. International Journal of ManMachine Studies, Vol.34, No.4, pp. 593-613, ISSN 00207373

Selwyn, N. (2004). The Information Aged: A Qualitative Study of Older Adults' Use of Information and Communications Technology. Journal of Aging Studies, Vol.18, No.4, (November 2004), pp. 369-384, ISSN 0890-4065

Shneiderman, B. (1991). Touch Screens Now Offer Compelling Uses. Software, IEEE, Vol.8, No.2, (March 1991), pp. 93-94, ISSN 0740-7459

Shneiderman, B. (2006). The Limits of Speech Recognition. Communications of ACM, Vol.43, No.9, (September 2000), pp. 63-65

Siek, K.A., Khan, D.U., Ross, S.E., Haverhals, L.M., Meyers, J., \& Cali, S.R. (2011). Designing a Personal Health Application for Older Adults to Manage Medications: A Comprehensive Study. Journal of Medical Systems, DOI 10.1007/s10916-011-9719-9

Smith, L. (August 2010). Self-Service, or Merely Self-Serving? The Revolution at the Tills, In: The Independent, 01.08.2011, Available from

http://www.independent.co.uk/news/uk/home-news/selfservice-or-merelyselfserving-the-revolution-at-the-tills-2059363.html

Stöbel, C. (2009). Familiarity as a Factor in Designing Finger Gestures for Elderly Users, Proceedings of Human-Computer Interaction with Mobile Devices and Services (MobileHCI '09), ISBN 978-1-60558-281-8, Bonn, Germany, September 15-18, 2009

Strauss, M. (August 2009). Touch Screen Button Dimensions and Spacing: Hell if Phi Know, In: Home Technology E-Magazine, 10.07.2011, Available from http://www.hometoys.com/ezine/09.08/strauss/

Sukumar, S. (1984). Touchscreen Personal Computer Offers Ease of Use and Flexibility. Hewlett-Packard Journal, Vol.35, No.8, (August 1984), pp. 4-6 
Tsai, T., Chang, H., Wong, A.M., \& Wu, T. (2011). Connecting Communities: Designing a Social Media Platform for Older Adults Living in a Senior Village. Universal Access in Human-Computer Interaction, Vol. 6766, (July 2011), pp. 224-233

Umemuro, H. (2004). Lowering Elderly Japanese Users' Resistance towards Computers by Using Touchscreen Technology. Universal Access in the Information Society, Vol.3, No.3, (July 2004), pp. 276-288

Wagner, N., Hassanein, K., \& Head, M. (2010). Computer Use by Older Adults: A MultiDisciplinary Review. Computers in Human Behaviour, Vol.26, No.5, (September 2010), pp. 870-882, ISSN 07475632

Waloszek, G. (2000). Interaction Design Guidelines for Touchscreen Applications, In: Sap Design Guild, 26.02.11, Available from http://www.sapdesignguild.org/resources/tsdesigngl/index.htm

Wright, P., Soroka, A., Belt, S., Pham, D.T., Dimov, S., Roure, D.D., \& Petrie, H. (2010). Using Audio to Support Animated Route Information in a Hospital Touch-Screen Kiosk. Computers in Human Behavior, Vol.26, No.4, (February 2010), pp. 753-759, ISSN 07475632

Yost, K.J., Webster, K., Baker, D.W., Jacobs, E.A., Anderson, A., \& Hahn, E.A. (2010). Acceptability of the Talking Touchsceen for Health Literacy Assessment. Journal of Health Communication, Vol.15, No.2, (September 2010), pp. 80-92

Ziefle, M. (2010). Information Presentation in Small Screen Devices: The Trade-Off between Visual Density and Menu Foresight. Applied Ergonomics, Vol. 40, No.6, (October 2010), pp. 719-730 


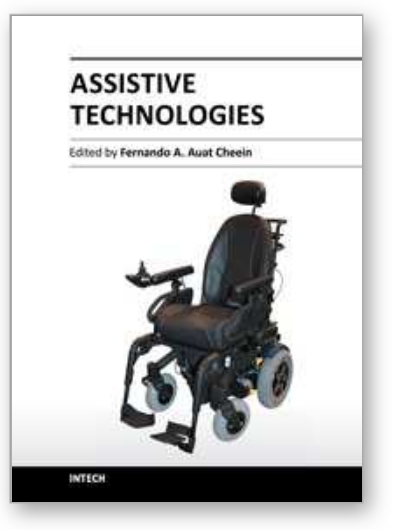

\author{
Assistive Technologies \\ Edited by Dr. Fernando Auat Cheein
}

ISBN 978-953-51-0348-6

Hard cover, 234 pages

Publisher InTech

Published online 16, March, 2012

Published in print edition March, 2012

This book offers the reader new achievements within the Assistive Technology field made by worldwide experts, covering aspects such as assistive technology focused on teaching and education, mobility, communication and social interactivity, among others. Each chapter included in this book covers one particular aspect of Assistive Technology that invites the reader to know the recent advances made in order to bridge the gap in accessible technology for disabled or impaired individuals.

\title{
How to reference
}

In order to correctly reference this scholarly work, feel free to copy and paste the following:

Niamh Caprani, Noel E. O'Connor and Cathal Gurrin (2012). Touch Screens for the Older User, Assistive Technologies, Dr. Fernando Auat Cheein (Ed.), ISBN: 978-953-51-0348-6, InTech, Available from: http://www.intechopen.com/books/assistive-technologies/touch-screens-for-the-older-user

\section{INTECH}

open science | open minds

\author{
InTech Europe \\ University Campus STeP Ri \\ Slavka Krautzeka 83/A \\ 51000 Rijeka, Croatia \\ Phone: +385 (51) 770447 \\ Fax: +385 (51) 686166 \\ www.intechopen.com
}

\author{
InTech China \\ Unit 405, Office Block, Hotel Equatorial Shanghai \\ No.65, Yan An Road (West), Shanghai, 200040, China \\ 中国上海市延安西路65号上海国际贵都大饭店办公楼405单元 \\ Phone: +86-21-62489820 \\ Fax: $+86-21-62489821$
}


(C) 2012 The Author(s). Licensee IntechOpen. This is an open access article distributed under the terms of the Creative Commons Attribution 3.0 License, which permits unrestricted use, distribution, and reproduction in any medium, provided the original work is properly cited. 